Jurnal Konstruksi Hukum | ISSN: XXXX | E-ISSN: XXXX Vol. 1, No. 1, September 2020 Hal. 135-139| Available online at https://www.ejournal.warmadewa.ac.id/index.php/jukonhum DOI: https://doi.org/10.22225/jkh.1.1.2146.135-139

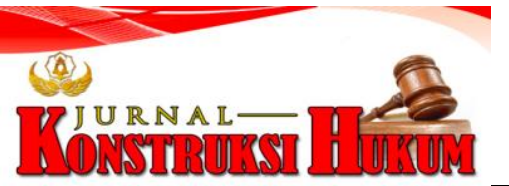

\title{
PERLINDUNGAN HUKUM BAGI KONSUMEN DALAM TRANSAKSI JUAL BELI MELALUI MEDIA ELEKTRONIK DENGAN SISTEM "DROPSHIP"
}

\author{
Gusti Ayu Dwi Dhyana Amrita, Ni Luh Made Mahendrawati, Ni Made Puspasutari Ujianti \\ Fakultas Hukum Universitas Warmadewa, Denpasar-Bali, Indonesia
}

\begin{abstract}
Abstrak
Kegiatan jual beli dengan menggunakan sistem dropship merupakan suatu kegiatan perdagangan di mana penjual tidak mempunyai stok barang yang ia jual, melainkan hanya mempromosikan barang lewat gambar yang diunggah ke toko online miliknya. Apabila penjual mendapatkan pesanan dari konsumen, penjual tersebut tidak dapat memastikan secara langsung kondisi barang yang akan dikirim kepada konsumen karena pihak supplier yang akan mengirimkannya menggunakan identitas penjual. Penelitian ini bertujuan untuk mengetahui dan mengkaji perlindungan hukum terhadap konsumen dalam jual beli melalui media elektronik dengan menggunakan sistem dropship, dan untuk mengetahui dan mengkaji akibat hukum yang ditimbulkan jika terjadi wanprestasi dalam jual beli melalui media elektronik dengan menggunakan sistem dropship. Hasil penelitian menunjukkan bahwa perlindungan hukum terhadap konsumen dalam jual beli melalui media elektronik dengan menggunakan sistem dropship dapat dilakukan secara preventif dan represif, dan akibat hukum yang ditimbulkan jika terjadi wanprestasi dalam jual beli menggunakan sistem dropship yaitu kerugian yang dialami oleh konsumen merupakan tanggung jawab penjual karena penjual merupakan pihak yang membuat perjanjian langsung dengan konsumen bukan supplier. Oleh karena itu, masyarakat diharapkan lebih berhati-hati dalam melakukan transaksi melalui media elektronik supaya tidak mengalami kerugian sendiri.
\end{abstract}

Kata Kunci: Perlindungan hokum; Jual beli; Dropship

\begin{abstract}
The activity of buying and selling using the dropshipping system is a trading activity in which the seller does not have stock of the goods he is selling, but only promotes goods through images uploaded to his or her online shop. If the seller gets an order from a consumer, the seller cannot directly confirm the condition of the goods to be sent to the consumer because the supplier who will send it uses the seller's identity. This study aims to determine and study legal protection for consumers in buying and selling via electronic media using the dropshipping system, and to find out and study the legal consequences that arise if there is default in buying and selling via electronic media using the dropshipping system. The results showed that legal protection for consumers in buying and selling through electronic media using the dropshipping system can be done in a preventive and repressive manner, and the legal consequences that arise if there is default in buying and selling using the dropshipping system, namely the loss suffered by consumers is the responsibility of the seller because The seller is the party who makes a direct agreement with the consumer, not the supplier. Therefore, the public is expected to be more careful in conducting transactions via electronic media so that they do not suffer their own losses.
\end{abstract}

Keywords: Legal protection; Buying and selling; Dropship

\section{PENDAHULUAN}

Kegiatan perdagangan melalui media elektronik (E-commerce) memudahkan manusia untuk melakukan transaksi jual beli. Dengan adanya perdagangan melalui (E-commerce) manusia bisa membeli barang atau menggunakan suatu jasa tanpa harus bertatap muka langsung dengan penjual. Hanya dengan membuka situs website atau aplikasi online yang menyediakan fasilitas kegiatan jual beli online dari berbagai toko, kita bisa mencari, memilih dan mendapatkan barang yang kita inginkan. Semakin berkembangnya perdagangan melalui media elektronik ini menimbulkan adanya sistem penjualan Dropshipping. Dropshipping kini menjadi salah satu model bisnis yang banyak diminati oleh pembisnis online karena tidak memerlukan modal besar, sebab dropship (toko online) tidak pernah menyetok dan menyediakan tempat penyetokan barang melainkan hanya 
mempromosikan melalui toko online dengan memasang foto serta mencantumkan kriteria barang dan harga. Barang didapat dari jalinan kerja sama dengan perusahaan lain yang memiliki barang yang sesungguhnya (Feri, 2014). Sistem dropship ini banyak diminati karena dengan adanya sistem dropship ini membuka peluang bagi siapa saja untuk memulai bisnis secara online dengan modal usaha yang kecil dan waktu yang fleksibel (Bariroh, 2016). Namun, dalam sistem dropship ini pelaku usaha tidak memiliki stok barang yang ia jual melainkan hanya mengunggah atau memperlihatkan gambar serta rincian produk yang ia peroleh dari supplier kepada konsumen, maka apabila pelaku usaha tersebut mendapatkan pesanan, ia tinggal meneruskan pemesanan barang kepada supplier dan supplier lah yang langsung mengirimkan barang kepada konsumen atas nama pelaku usaha dropship tersebut, sehingga pelaku usaha tidak mengetahui secara pasti apakah kondisi barang yang ia jual sudah sesuai dengan barang yang dikirimkan oleh supplier kepada konsumennya. Hal ini tentu dapat menimbulkan permasalahan jika terjadi ketidaksesuaian antara barang yang dijual oleh pelaku usaha dropship dan barang yang dikirim oleh supplier kepada konsumen tersebut. Selain itu, sistem dropship juga dapat menimbulkan permasalahan dalam hal ketepatan waktu pengiriman kepada konsumen. Konsep transaksi dropshipping dalam dunia bisnis adalah transaksi jual beli pesanan secara online namun penjual (dropship) tidak pernah menyimpan barang dan mengurus pengiriman barang ke konsumen, melainkan pemilik barang (dropshipper) yang melakukannya tetapi mengatasnamakan toko online (dropship) (Rudiana \& Basami, 2016). Pelaku usaha tidak dapat memantau secara langsung proses pengiriman yang dilakukan oleh supplier, sehingga dapat terjadi keterlambatan dalam hal pengiriman. Dalam sistem dropship, konsumen tidak mengetahui bahwa barang yang ia pesan bukan berasal dari penjual selaku pihak pertama itu langsung melainkan dari supplier selaku pihak ke dua. Sedangkan, pelaku usaha memiliki kewajiban untuk memberikan informasi yang benar, jelas dan jujur mengenai kondisi dan jaminan barang dan/atau jasa serta memberikan penjelasan penggunaan, perbaikan dan pemeliharaan sebagaimana yang telah diatur pada Pasal 7 huruf $b$ UUPK.

Berdasarkan uraian di atas, penilaian ini bertujuan untuk mengetahui dan mengkaji perlindungan hukum terhadap konsumen dalam jual beli melalui media elektronik dengan menggunakan sistem dropship, dan untuk mengetahui dan mengkaji akibat hukum yang ditimbulkan jika terjadi wanprestasi dalam jual beli melalui media elektronik dengan menggunakan sistem dropship.

\section{METODE PENELITIAN}

Dalam penelitian ini, tipe penelitian yang digunakan merupakan penelitian hukum normatif. Pendekatan yang digunakan yaitu pendekatan perundang-undangan dan pendekatan konsep yang berkaitan dengan perlindungan konsumen dan transaksi melalui media elektronik. Sumber bahan hukum yang digunakan dalam penelitian ini adalah bahan hokum primer, bahan hukum sekunder dan bahan hukum tersier. Bahan hukum primer bersumber dari bahan hukum yang diperoleh langsung yang akan digunakan dalam penelitian ini yang mempunyai kekuatan mengikat secara yuridis, yaitu: Kitab Undang-Undang Hukum Perdata, Undang-Undang Republik Indonesia Nomor 8 Tahun 1999 Tentang Perlindungan Konsumen, Undang- Undang Nomor 11 Tahun 2008 Tentang Informasi dan Transaksi Elektronik. Bahan hukum sekunder adalah bahan hukum yang diperoleh dari buku atau literatur, karya ilmiah, jurnal hukum, situs web, artikel-artikel, pendapat sarjana yang berkaitan dengan materi penelitian. Bahan hukum tersier yaitu bahan-bahan yang memberikan petunjuk maupun penjelasan terhadap bahan hukum primer dan bahan hukum sekunder seperti kamus. Teknik Pengumpulan Bahan Hukum yang digunakan dalam penelitin ini adalah dengan cara mengkaji, mengumpulkan dan mengolah secara sistematis bahan- bahan kepustakaan dan dengan menganalisis peraturan perundang-undangan.

\section{HASIL PENELITIAN DAN PEMBAHASAN}

1. Perlindungan Hukum terhadap Konsumen Dalam Jual Beli Melalui Media Elektronik dengan Menggunakan Sistem Dropship

Dropship merupakan suatu kegiatan perdagangan di mana penjual tidak menyimpan stok barang yang ia jual. Jika penjual mendapatkan pesanan, penjual tersebut langsung meneruskan pesanan dan detail pengiriman barangnya ke distributor/supplier/produsen (Cahyadi, 2018). Adapun 
mekanisme penjualan dengan menggunakan sistem dropship ini yaitu (Hadi, 2012) seorang dropshipper (penjual yang menggunakan sistem dropship) mempromosikan produk dagangannya dengan mengunggah gambar, video, serta rincian produk yang diperoleh dari pihak supplier di toko online milik dropshipper itu sendiri atau sosial media. Kemudian, apabila konsumen yang melihat iklan penjualan barang dari dropshipper di media sosial atau toko online dan tertarik dengan produk yang di jual, maka konsumen dapat memesan barang tersebut dan membayar produk pesanan sesuai dengan harga jual yang telah ditentukan oleh dropshipper. Setelah menerima pembayaran dari konsumen, dropshipper menghubungi supplier dan memastikan ketersediaan barang yang di pesan oleh konsumen kepada supplier, kemudian membayar produk sesuai dengan pesanan konsumen dengan harga jual dari supplier serta menyertakan rincian biodata konsumen (nama, alamat, nomor telepon) dan nama toko atau nama usaha dropshipper. Setelah mendapatkan pesanan dari dropshipper, kemudian supplier mengirimkan barang sesuai dengan pesanan dari dropshipper dan menyertakan barang tersebut dikirim atas Nama dropshipper.

Kegiatan jual beli online diatur dalam Undang-Undang Informasi dan Transaksi Elektronik Nomor 11 Tahun 2008 (UU ITE). Namun, berkaitan dengan perdagangan menggunakan sistem dropship, masih terdapat kekosongan norma karena belum diatur secara khusus di dalam perundangan di Indonesia. Karena belum adanya peraturan mengenai dropship ini, maka para pihak dalam melakukan perjanjian harus berdasarkan asas-asas dalam perjanjian serta harus memenuhi syarat sahnya perjanjian sebagaimana yang tercantum dalam Pasal 1320 KUHPerdata dan oleh karena kegiatan jual beli menggunakan sistem dropship ini termasuk dalam transaksi elektronik karena dilakukan secara online melalui internet, maka para pihak dalam melakukan perjanjian juga harus berdasarkan ketentuan kontrak elektronik yang digunakan sebagai payung hukum dalam melakukan kegiatan jual beli menggunakan sistem dropship.

Perlindungan hukum merupakan suatu upaya untuk melindungi kepentingan seseorang serta bertujuan untuk memberikan perlindungan kepada masyarakat (Rahardjo, 1983). Perlindungan hukum terhadap konsumen dalam jual beli melalui media elektronik dengan menggunakan sistem dropship dapat dilakukan secara preventif dan represif (M.Hadjon, 2007). Perlindungan hukum secara preventif dalam jual beli dengan menggunakan sistem dropship ini berfungsi untuk mencegah agar konsumen tidak dirugikan. Perlindungan secara preventif yang dapat diberikan pelaku usaha dalam melindungi konsumen yaitu dengan melaksanakan kewajiban sebagaimana yang diatur dalam Undang-Undang Nomor 8 Tahun 1999 Tentang Perlindungan Konsumen (UUPK) khususnya yang tercantum pada Pasal 7 yang mengatur kewajiban pelaku usaha dan Pasal 8 yang mengatur tentang perbuatan yang dilarang bagi pelaku usaha. Berdasarkan peraturan tersebut, jika pelaku usaha memenuhi kewajiban sebagaimana yang tercantum pada Pasal 7 UUPK khususnya pada huruf a yaitu pelaku usaha harus beritikad baik dalam melakukan usahanya, maka dapat mencegah terjadinya wanprestasi pada suatu perjanjian. Itikad baik dalam suatu perjanjian dapat diartikan, bahwa suatu perjanjian hendaklah dilakukan dengan niat yang baik, jujur dan bersih sehingga, dalam pelaksanaannya nanti tercermin kepastian hukum dan rasa adil bagi para pihak yang terikat dalam perjanjian tersebut. Apabila pelaku usaha menghindari larangan sesuai yang tercantum pada Pasal 8 UUPK, serta melaksanakan kegiatan dengan berdasarkan ketentuan transaksi elektronik sebagaimana yang diatur dalam UU ITE maka hak-hak konsumen akan terpenuhi dan dapat mencegah terjadinya pelanggaran terhadap hak-hak konsumen (Setyawati et al., 2017).

Selanjutnya, perlindungan hukum secara represif dalam hal penyelesaian sengketa dibagi menjadi dua yaitu melalui jalur litigasi dan non litigasi (Wahyuni, 2018). Penyelesaian Sengketa Melalui Jalur Litigasi,yakni setiap orang yang merupakan konsumen dari internet yang mengalami kerugian dapat mengajukan gugatan melalui lembaga pengadilan sesuai dengan Pasal 38 UU ITE menjelaskan bahwa para pihak dapat menggugat apabila dalam penyelenggaraan transaksi elektronik merugikan pihak lain. Para pihak yang mengalami kerugian dapat menuntut pelaku usaha dengan Pasal 1244 KUHPer serta Pasal 28 ayat (1) UU ITE diancam pidana sebagaimana diatur dalam Pasal 45 A ayat (1) Undang-Undang Republik Indonesia Nomor 19 Tahun 2016 Tentang Perubahan atas Undang-Undang Nomor 11 Tahun 2008 Tentang Informasi dan Transaksi Elektronik. Sedangkan, penyelesaian sengketa Melalui Jalur Non Litigasi yakni Penyelesaian dari permasalahan konsumen menurut Undang-Undang Perlindungan Konsumen, dapat dipecahkan melalui jalan peradilan maupun non- peradilan. Penyelesaian sengketa konsumen di luar pengadilan menurut Pasal 47 UUPK diselenggarkan untuk mencapai kesepakatan mengenai bentuk dan besarnya ganti 
rugi dan/atau mengenai tindakan tertentu untuk menjamin agar kerugian yang dialami konsumen tidak akan terjadi kembali atau tidak akan terulang kembali. Penyelesaian dengan cara non-peradilan bisa dilakukan melalui Alternatif Resolusi Masalah (ARM) di LPKSM, BPSK, Direktorat Perlindungan Konsumen atau lokasi- lokasi lain baik untuk kedua belah pihak yang telah disetujui.

\section{Akibat Hukum yang Ditimbulkan dari Wanprestasi dalam Jual Beli Melalui Media Elektronik Dengan Menggunakan Sistem Dropship}

Wanprestasi menurut kamus hukum, merupakan kelalaian, kealpaan, cidera janji, tidak menepati kewajibannya dalam perjanjian. Dengan demikian, apabila seorang debitur (berutang) tidak dapat memenuhi kewajiban atau perstasinya sebagaimana yang telah disepakati dalam suatu perjanjian, maka debitur tersebut dapat dikatakan telah melakukan wanprestasi. Dalam kegiatan jual beli menggunakan sistem dropship, dropshipper selaku pihak yang telah melakukan perjanjian kepada konsumenlah yang memiliki tanggung jawab atas kerugian yang dialami konsumen karena, konsumen tidak mengetahui bahwa barang yang ia pesan bukan berasal dari penjual (drop shipper) itu langsung melainkan dari supplier. Maka akibat hukum yang timbul dari wanprestasi dalam jual beli menggunakan sistem dropship yaitu (Prabowo et al., 2016); apabila terjadi cacat atau kerusakan pada barang yang diterima oleh konsumen Konsumen berhak meminta ganti rugi kepada drop shipper apabila barang yang diterima mengalami kerusakan atau cacat. Drop shipper selaku pihak yang membuat perjanjian dengan konsumen harus mengganti kerugian yang dialami konsumen karena telah melakukan wanprestasi. Akan tetapi supplier biasanya akan membantu apabila barang tersebut rusak karena kesalahan supplier. Barang yang rusak atau cacat tersebut akan dikembalikan kepada supplier dengan biaya pengiriman ditanggung oleh konsumen. Kemudian, apabila barang pesanan terlambat datang maka drop shipper dianggap melakukan wanprestasi dalam hal terlambat melakukan perbuatan sesuai dengan prestasinya. Atas keterlambatan tersebut, drop shipper harus menanggung segala kerugian yang dialami konsumen karena tidak sesuai dengan perjanjian yang dilakukan antara drop shipper dengan konsumen. Yang terakhir, apabila konsumen tidak menerima barang yang di pesan dari dropshipper, kerugian akan dialami oleh konsumen apabila barang yang dibelinya tidak sampai kepadanya. Jika demikian, maka dropshipper telah melakukan wanprestasi karena drop shipper sama sekali tidak melaksanakan kewajibannya. Jika hal ini terjadi, maka pihak dropshipper biasanya mengganti kerugian dengan mengembalikan uang yang telah dibayar oleh konsumen.

Drop shipper selaku pelaku usaha memiliki kewajiban untuk memeberikan informasi yang benar dan lengkap mengenai produk yang ditawarkan. Dengan demikian, seorang drop shipper harus berhati-hati dalam mencari supplier untuk melakukan kerjasama agar dapat terhindar dari resiko terjadinya wanprestasi. Karena, drop shipper tidak memiliki produk yang ia jual dan tidak dapat memastikan secara langsung keadaan produk yang dikirim oleh supplier apakah sudah sesuai dengan produk yang dipesan oleh konsumennya, maka ia harus bersedia jika mendapatkan komplain dari konsumen apabila terjadi permasalahan pada produk yang dikirimkan seperti produk yang diterima cacat atau produk tidak sesuai dengan kesepakatan, karena drop shipper merupakan pihak yang melakukan perjanjian dengan konsumen tersebut sedangkan supplier merupakan pihak yang melakukan perjanjian kepada drop shipper sehingga supplier bertanggung jawab kepada dropshipper bukan konsumen itu langsung.

\section{SIMPULAN DAN SARAN}

\section{Simpulan}

Berdasarkan uraian di atas, dapat disimpulkan bahwa pelindungan hukum terhadap konsumen dalam jual beli melalui media elektronik dengan menggunakan sistem dropship dapat dilakukan secara preventif dan represif. Preventif yaitu untuk mencegah agar konsumen tidak dirugikan sedangkan secara represif yaitu bertujuan untuk menyelesaikan sengketa. Perlindungan secara preventif yang dapat diberikan pelaku usaha dalam melindungi konsumen yaitu dengan melaksanakan kewajiban sebagaimana yang diatur dalam pasal 7 UUPK khususnya pada huruf a yaitu pelaku usaha harus beritikad baik dalam melakukan usahanya untuk mencegah terjadinya wanprestasi pada suatu perjanjian dan apabila pelaku usaha menghindari larangan sesuai yang tercantum pada Pasal 8 UUPK, serta melaksanakan kegiatan dengan berdasarkan ketentuan transaksi elektronik sebagaimana yang diatur dalam UU ITE, maka hak-hak konsumen akan terpenuhi dan dapat mencegah terjadinya pelanggaran terhadap hak-hak konsumen tersebut. Sedangkan perlindungan 
hukum secara represif dalam hal penyelesaian sengketa dibagi menjadi dua yaitu melalui jalur litigasi dan non litigasi. Kemudian, akibat hukum yang ditimbulkan jika terjadi wanprestasi dalam jual beli menggunakan sistem dropship adalah pihak drop shipper selaku pihak yang membuat perjanjian dengan konsumen yang harus bertanggungjawab atas kerugian yang dialami oleh konsumen dengan memberikan ganti rugi ataupun membantu dalam hal pengembalian barang yang tidak sesuai dengan perjanjian yang telah disepakati oleh konsumen. Apabila terjadi tindak penipuan maka pelaku usaha dapat dituntut dengan Pasal 1244 KUH Per serta Pasal 28 ayat (1) UU ITE diancam pidana sebagaimana diatur dalam Pasal 45 A ayat (1) Undang- Undang Republik Indonesia Nomor 19 Tahun 2016 Tentang Perubahan atas Undang-Undang Nomor 11 Tahun 2008 Tentang Informasi dan Transaksi Elektronik.

\section{Saran}

Berdasarkan hasil penelitian, disarankan beberapa hal yakni bagi pemerintah; diharapkan untuk membuat peraturan terkait dengan kegiatan jual beli melalui media elektronik dengan sistem dropship, karena belum diatur secara khusus untuk mencegah timbulnya wanprestasi dalam jual beli menggunakan sistem dropship ini. Kemudian, bagi masyarakat selaku konsumen dalam kegiatan jual beli melalui media elektronik secara online diharapkan untuk lebih berhati-hati dan teliti memilih toko online dalam berbelanja untuk mencegah terjadinya penipuan.

\section{DAFTAR PUSTAKA}

Bariroh, M. (2016). Transaksi Jual Beli Dropshipping Dalam Perspektif Fiqh Muamalah. Ahkam: Jurnal Hukum Islam, 4(2), 199-216.

Cahyadi, I. F. (2018). Sistem Pemasaran Dropship dalam Perspektif Islam. TAWAZUN : Journal of Sharia Economic Law, 1(1), 24.

Feri, S. (2014). Terobosan Berjualan Online Ala Dropshipping. Andi.

Hadi, P. C. (2012). Jualan Online Tanpa Repot Dengan Dropshipping. PT Elex Media Komputindo.

M.Hadjon, P. (2007). Perlindungan Hukum Bagi Rakyat Indonesia. Percetakan M2 Print.

Prabowo, B., Priyono, E. A., \& Hendrawati, D. (2016). Tanggung Jawab Dropshipper dalam Transaksi E-Commerce dengan Cara Dropship Ditinjau dari Undang-Undang Nomor 8 Tahun 1999 tentang Perlindungan Konsumen. Diponegoro Law Journal, 5(3), 1-14.

Rahardjo, S. (1983). Permasalahan Hukum di Indonesia. Alumni.

Rudiana, \& Basami, A. O. (2016). Transaksi Dropshipping Perspektif Ekonomi Syari'ah. AlMustashfa: Jurnal Penelitian Hukum Ekonomi Syariah, 3(1), 54-61.

Setyawati, D. A., Ali, D., \& Rasyid, M. N. (2017). Perlindungan Bagi Hak Konsumen dan Tanggung Jawab Pelaku Usaha dalam Perjanjian Transaksi Elektronik. Syiah Kuala Law Journal, 1(3), 3351.

Wahyuni, N. (2018). Perlindungan Hukum Bagi Konsumen Melalui Penyelesaian Sengketa Akibat Janji Iklan Perumahan. Jurnal Transparansi Hukum, 1(1), 19-36.

Kitab Undang-Undang Hukum Perdata (Burgerlijk Wetboek)

Undang-Undang Nomor 8 Tahun 1999 Tentang Perlindungan Konsumen.

Undang-Undang Nomor 11 Tahun 2008 Tentang Informasi dan Transaksi Elektronik. Undang-

Undang Republik Indonesia Nomor 19 Tahun 2016 Tentang Perubahan atas

Undang-Undang Nomor 11 Tahun 2008 Tentang Informasi dan Transaksi Elektronik. 